\title{
CONTROL SUBMECHANISM OF MECHANISM OF ENERGY SAVING MANAGEMENT IN THE SYSTEM OF HIGHER EDUCATION INSTITUTIONS
}

\author{
O. Shevchenko ${ }^{1}$
}

DOI: http://doi.org/10.15350/L_3/3/2

Abstract

The definition of control submachinism as a set of functions of control and monitoring of the activity of energy saving management entity at different levels is substantiated, which is realized through the formation of an information database on the effectiveness of the MESMSHEI and the energy conservation policy implementation.

In the structure of the control submechanism MESMSHEI, which is realized by State Energy Efficiency, five blocks are distinguished: 1) involvement in energy saving activities; 2) state registration; 3) accreditation and implementation of energy saving activity; 4) monitoring in the field of energy saving; 5) control in the field of energy saving - by which tasks and functions of energy saving are distributed.

The peculiarities of implementation of performance-contracting concept in Ukraine are analyzed, the features of the control organization over using energy service contracts are determined, that allowes to distinguish five main blocks. The study of the interaction of subjects and objects of energy conservation within the energy service reveales the role of individual subjects in adoption, approval, regulation of the implementation of management decisions. The assorting of the control submechanism units in the implementation of the energy service technology confirmes the compliance of the control structure with the control submechanism, which is being implemented by the State Department of Energy Efficiency in the process of fulfilling the main tasks and functions, which makes it possible to improve and systematize the legislative and normative provision of energy saving.

Keywords: energy saving, control submachinism, mechanism of energy saving management in the system of higher education institutions, performancecontract.

Постановка проблемы и ее связь с важными научными и практическими задачами. В Украине в результате завершения реструктуризации энергетических компаний и становления энергорынков возникла энергетическая неопределенность. Она генерирует угрозы деятельности для субъектов энергетики: изменчивость розничного потребления, расширение при-

\footnotetext{
${ }^{1}$ Oleg Shevchenko, Director of the Project Office, Kiev National University of Technology and Design, Kiev, Ukraine.
} 
менения «зеленого тарифа» на генерацию электроэнергии из возобновляемых источников, неплатежеспособность потребителей, ограничение дотирования и субсидирования населения и бюджетных учреждений, развитие генерации электроэнергии из возобновляемых источников энергоресурсов, - которые перекладываются на потребителей путем повышения тарифов и повышения доли инвестиционной составляющей в них .

В последние годы существенно выросли расходы учреждений высшего образования на энергопотребление за счет отмены дифференцированной системы тарифов. Из-за недофинансирования из бюджета высшие учебные заведения вынуждены использовать собственные поступления от хозяйственной деятельности для оплаты услуг по энергоснабжению и теплоснабжению. При таких условиях эффективность энергосбережения в вузе приобретает ключевое значение для успешного его существования, а результаты определяются эффективностью контрольной составляющей механизма управления энергосбережением.

Похожая ситуация в 90-х годах XX века стимулировала энергетические компании США и Западной Европы искать новые возможности расширения спектра предоставления и охвата услугами потребителей за счет инвестирования в энергосбережение и энергоэффективность потребления. Для решения поставленных задач было использовано технологию перфоманс-контрактинга путем создания дочерних предприятий для инвестирования в внедрение энергосберегающих мероприятий в образовательной сфере.

Анализ последних публикаций по проблеме исследования. В Ежегодном послании Президента Украины к Верховной Раде Украины «О внутреннем и внешнем положении Украины в 2015 году» отмечается необходимость конвергенции науки, образования и предпринимательства, а государственная политика должна способствовать этому, стимулируя расширение возможностей финансирования инновационных разработок и их внедрения [1]. К приоритетным направлениям государственной политики отнесены энергосбережение и энергоэффективность.

Результаты изучения теоретических и практических проблем энергосбережения отражены в работах А. Амоши, А. Бауэна, А. Вигдорчик, К. Гилингема, Л. Головановой, Г. Грубы, К. Демирчана, С. Денисюка, Р. Джемилева, Г. Дзянь, П. Дияка, Г. Дугинец, П. Дьюти, И. Зарембы, М. Ковалко, 0. Ливинского, Л. Лум, И. Мартинсона, В. Микитенко, Я. Николайдиса, Ю. Орловской, Д. Оуянг, К. Палмера, П. Пирсона, О. Поповченко, О. Праховика, В. резво, Ж. Ричарда, К. Ромамерти, Т. Салашенко, Л. Саркисян, Ю. Свирчевский, О. Ставицкой, О. Суходоли, В. Черниковой, А. Шидловского и других. Исследованные научные работы по энергосбережению рассматривают его как процесс сохранения энергетических ресурсов, характеризуют концепции внедрения энергосберегающих технологий в процессе строительства и реконструкции зданий и сооружений или отдельные аспекты применения инструментов и механизмов энергосбережения в Украине.

Учитывая результаты известных исследований, дополнительного изучения заслуживает контрольный подмеханизм механизма управления 
энергосбережением в системе высших учебных заведений, ибо обеспечивает регламентацию, регулирование, надзор и возможность внедрения новых инструментов для совершенствования организации указанного аспекта деятельности вуза за счет систематизации.

Цель исследования предполагает определение содержания, строения, особенностей действия контрольного подмеханизма механизма управления энергосбережением в системе высших учебных заведений и поиск направлений его совершенствования.

Изложение основных результатов иследования и их обоснование. Учитывая особенности дефиниции категорий «механизм управления» и «механизм государственного управления» предлагаем рассматривать контрольный подмеханизм как совокупность функций контроля и мониторинга деятельности субъектов управления энергосбережением разных уровней, который реализуется через формирование информационной базы данных об эффективности функционирования МУЕСВУЗ и реализацию политики энергосбережения.

Контроль и надзор в сфере энергосбережения обеспечивают Кабинет Министров Украины, НКРЕКП, Госэнергоэффективности.

НКРЕКП осуществляет содействие внедрению мероприятий по энергоэффективности, увеличению доли производства энергии из возобновляемых источников энергии и защиты окружающей среды; устанавливает минимальные стандарты и требования к качеству обслуживания потребителей и поставки природного газа, электрической и тепловой энергии, осуществляет мониторинг их соблюдения; обеспечивает в соответствии с законодательством доступ потребителей к информации о ценах/тарифах в сферах снабжения электрической энергией, природным газом, в сферах теплоснабжения, централизованного водоснабжения и водоотведения; проводит консультации с Секретариатом Энергетического Сообщества с целью получения выводов по применению европейского энергетического права; осуществляет государственный контроль за соблюдением субъектами хозяйствования, осуществляющими деятельность в сферах энергетики и коммунальных услуг, законодательства в соответствующих сферах и лицензионных условий путем проведения плановых и внеплановых выездных, а также невыездных проверок в соответствии с утвержденными порядками контроля; осуществляет мониторинг оптовых и розничных цен на товары (услуги) на рынках в сферах энергетики и коммунальных услуг; мониторинг отсутствия проявлений перекрестного субсидирования между различными видами деятельности, категориями потребителей (заказчиков) на рынках в сферах энергетики и коммунальных услуг; оценку разработки и реализации инвестиционных программ и мероприятий по инвестиционному планированию в отношении операторов систем передачи, газотранспортной системы в краткосрочной и долгосрочной перспективе с целью повышения эффективности работы систем и содействия рыночной интеграции; мониторинг инвестиций в генерирующие мощности с целью обеспечения безопасности поставок электрической энергии и применения условий для присоединения к сетям новых генерирующих 
мощностей с должным учетом затрат и выгод, связанных с различными технологиями в использовании возобновляемых источников энергии, а также с распределенной генерацией и комбинированным производством тепловой и электрической энергии (когенерацией) и т.д. [2].

Государственная инспекция по энергетическому надзору Украины осуществляет контроль за соответствием новых и реконструированных электрических и тепловых установок и сетей техническим условиям, нормам, правилам и стандартам, обеспечивает подтверждение их готовности к работе; принимает участие в работе комиссий по приемке в промышленную эксплуатацию автоматизированных систем коммерческого учета энергии на установках субъектов электроэнергетики и объектов в сфере теплоснабжения; подготовку предложений по пересмотру нормативно-технической документации на энергетическое оборудование в случае его несоответствия требованиям Правил устройства электроустановок, Правил технической эксплуатации электроустановок потребителей, Правил технической эксплуатации систем теплоснабжения коммунальной энергетики, Правил эксплуатации тепловых установок и тепловых сетей; участие в случае необходимости в проведении экспертизы электро- и теплотехнической частей проектов строительства и реконструкции объектов заказчиков на соответствие требованиям; надзор за обеспечением надлежащего оперативно-диспетчерского управления энергохозяйством потребителей энергии и т.д. [3].

Деятельность Госэнергоэффективности в сфере энергосбережения, как центрального органа исполнительной власти, определяется и координируется через вице-премьер-министра Украины - Министра регионального развития, строительства и жилищно-коммунального хозяйства Кабинетом Министров Украины и направлена на реализацию государственной политики по обеспечению эффективного использования топливно энергетических ресурсов, энергосбережения, расширение использования возобновляемых источников энергии и альтернативных видов топлива.

Государственное агентство по энергоэффективности и энергосбережению Украины осуществляет контроль и мониторинг в разрезе определенных задач его деятельности, поэтому можно выделить следующие блоки контрольного подмеханизма управления энергосбережением:

Блок 1 «Привлечение к деятельности по энергосбережению» предусматривает: 1) анализ и обобщение практики применения законодательства по вопросам энергоэффективности и энергосбережения и разработки предложений по совершенствованию регуляторной деятельности (финансового и нормативного регулирования); 2) подготовку международных договоров Украины и обеспечивает их выполнение в соответствии с законодательством; заключает международные договоры Украины межведомственного характера; осуществляет адаптацию национального законодательства к законодательству ЕС; выполнение мероприятий по имплементации в национальное законодательство положений международных договоров, стороной которых является Украина; международное сотрудничес- 
тво; 3) участие в пределах своих полномочий в налаживании сотрудничества Украины с Европейским Союзом, Европейским Сообществом по атомной энергии и их государствами-членами в сфере эффективного использования топливно-энергетических ресурсов, энергосбережения, возобновляемых источников энергии и альтернативных видов топлива; 4) информационную деятельность по популяризации экономических, экологических и социальных преимуществ эффективного использования топливно-энергетических ресурсов, энергосбережения, возобновляемых источников энергии и альтернативных видов топлива; 5) организацию обучения и подготовку предложений по совершенствованию системы подготовки и переподготовки специалистов в сфере эффективного использования топливно-энергетических ресурсов, энергосбережения, возобновляемых источников энергии и альтернативных видов топлива; 6) разработку предложений по стимулированию энергосбережения, эффективного использования топливно-энергетических ресурсов, возобновляемых источников энергии и альтернативных видов топлива и осуществление мониторинга их применения; 7) содействие организации публичных закупок энергосервиса установлением и регламентацией процедуры открытых торгов или переговорной процедуры закупки согласно действующего порядка [4] закупок услуг, с учетом особенностей технологии энергосервиса;

Блок 2 «Государственная регистрация» воплощается в: 1) ведение Государственного реестра предприятий, учреждений, организаций, осуществляющих разработку, внедрение и использование энергоэффективных мероприятий и энергоэффективных проектов; 2) ведение реестра альтернативных видов топлива и государственного реестра производителей жидких биологических видов топлива и биогазовых;

Блок 3 «Аккредитация и реализация деятельности по энергосбережению» заключается в следующем: 1) реализации государственно-частного партнерства в сфере эффективного использования топливно-энергетических ресурсов, энергосбережения, возобновляемых источников энергии и альтернативных видов топлива; 2) документальном удостоверении принадлежности топлива к альтернативному; 3) квалификации когенерационных установок; 4) обеспечении функционирования системы энергетической маркировки электрооборудования бытового назначения; 5) создании фондов государственной поддержки мероприятий в сфере эффективного использования топливно-энергетических ресурсов, энергосбережения, возобновляемых источников энергии и альтернативных видов топлива;

Блок 4 «Мониторинг в сфере энергосбережения» включает: 1) создание и функционирование государственной системы мониторинга показателей энергетического баланса Украины; 2) мониторинг эффективности использованием топливно-энергетических ресурсов; 3) энергетический аудит; 4) анализ потенциала повышения энергетической эффективности зданий; 5) мониторинг энергосервисных услуг и их эффективности; 
Блок 5 «Контроль в сфере энергосбережения» осуществляется через: 1) разработку, согласование с НКРЕКП и осуществления контроля за выполнением государственных целевых программ в сфере эффективного использования топливно-энергетических ресурсов, энергосбережения, возобновляемых источников энергии и альтернативных видов топлива, согласовывает отраслевые, региональные и местные программы в этой сфере; 2) государственную экспертизу по энергосбережению; 3) введение энергетического менеджмента; 4) разработку и контроль соблюдения государственных норм, правил, технических регламентов и стандартов в сфере эффективного использования топливно-энергетических ресурсов, энергосбережения; 5) разработку критериев устойчивости для жидкого и газообразного топлива производится из биомассы; 6) выработку технических требований к производству и использованию биотоплива и биожидкостей с сокращением объемов выбросов парниковых газов.

Госэнергоэффективности осуществляет выдачу приказов организационно-распорядительного характера, организовывает и контролирует их выполнение [5].

В рамках первого блока «Привлечение к деятельности по энергосбережению» осуществляется разработка и выполнение Национального плана действий по энергоэффективности до 2020 года, Национального плана действий по возобновляемой энергетике до 2020 года, планов мероприятий по транспозиции европейских директив в сферах энергоэффективности и возобновляемой энергетики, подготовка регламентов в сферах энергоэффективности и энергосбережения, Плана мероприятий по внедрению систем энергоменеджмента в бюджетных учреждениях, Дорожной карты нормативно-правового обеспечения развития сфер энергоэффективности и возобновляемой энергетики.

Государственная регистрация предусматривает обнародование информации об иностранных партнерах Госэнергоэффективностью; ведение реестра альтернативных видов топлива; предоставление гарантий происхождения энергии, произведенной из ВИЭ и в процессе когенерации; создание и ведение базы данных инвестиционных проектов и технических решений; ведение реестра когенерационных установок; регистрацию эско-компаний, договоров и т.

Согласно блока «Аккредитация и реализация деятельности по энергосбережению» Министерства и другие центральные органы исполнительной власти разрабатывают и согласовывают с Госэнергоэффективностью программы уменьшения потребления энергоресурсов бюджетными учреждениями путем их рационального использования. Госэнергоэффективности методологически обеспечивает разработку отраслевых программ повышения энергоэффективности и программ уменьшения потребления энергоресурсов бюджетными учреждениями и разрабатывает проект Государственной целевой экономической программы энергоэффективности, учитывая содержание положений отраслевых программ повышения энергоэффективности. 
Блок 4 «Мониторинг в сфере энергосбережения» предусматривает построение карты теплых кредитов, позволяет установить интенсивность внедрения энергосбережения в бюджетной и жилищной сферах; введение энергетической сертификации зданий; осуществление энергетического аудита.

Министерства и другие центральные органы исполнительной власти с 2010 года до 10 числа второго месяца после завершения полугодия, направляют в Госэнергоэффективности информацию о выполнении отраслевых программ повышения энергоэффективности и программ уменьшения потребления энергоресурсов бюджетными учреждениями согласно утвержденным Агентством формам для ее обработки и доведения до Кабинета Министров Украины до 25 числа месяца ее сбора [6].

Блок 5 «Контроль в сфере энергосбережения» осуществляется через проведение энергетического аудита и создания эффективных систем управления и средств контроля за энергосбережением, путем использования системы государственных стандартов в сфере энергосбережения.

В рамках этого блока осуществляется государственная экспертиза по энергосбережению проектов развития отраслей народного хозяйства, территориальных схем энергообеспечения, энерготехнологической части технико-экономических обоснований и проектов строительства новых и расширения (реконструкции, технического обеспечения, модернизации) действующих объектов и предприятий при годовом потреблении ТЭР в тысячу и более тонн в пересчете на условное топливо - по обращению заказчика для предоставления преференций за счет бюджетных средств, проектов инструкций методических и нормативно-технических актов, строительных норм и правил, документации на создание и приобретение новой энергоемкой техники, другие документы и материалы, регламентирующие деятельность в сфере энергосбережения.

Заключение государственной экспертизы по энергосбережению является обязательным для применения льгот согласно действующему налоговому и таможенному законодательству, приоритетного кредитования мероприятий по обеспечению рационального использования и экономии топливно-энергетических ресурсов, получения безвозвратного ассигнования, целевых государственных и других субсидий, субвенций, дотаций для осуществления мероприятий по обеспечению энергосбережения за счет бюджетных средств [7].

При введении в вузах технологии комбинированного производства электрической и тепловой энергии или преобразования сбросного энергетического потенциала технологических процессов в электрическую и тепловую энергию производится квалификация когенерационной установки, которая заключается в определении Госэнергоэффективностью соответствия условий и показателей эксплуатации когенерационной установки действующим требованиям или квалификационным показателям [8, с. 2]. Использование когенерации требует лицензирования хозяйственной деятельности по комбинированному производству тепловой и электрической 
энергии осуществляет национальная комиссия по государственному регулированию в сфере энергетики; предоставления разрешений на установку или сооружение когенерационных установок на базе существующих энергетических объектов; установления тарифов на электрическую и тепловую энергию, производимые когенерационными установками [8, с. 3].

Деятельность по энергосбережению в высших учебных заведениях предусматривает проведение санации зданий учреждений, которые полностью содержатся за счет средств государственного бюджета. Санация это комплекс технических мероприятий по восстановлению и повышению теплотехнических характеристик зданий до уровня, установленного современными требованиями, нормами, стандартами, уменьшение потерь энергоресурсов и воды, улучшение условий пребывания работников. В рамках санации выполняются: термоизоляция внешних стен здания, подвала и фундамента; модернизация кровли с возможным установлением на ней солнечных коллекторов модернизация тепловых, водопроводных, канализационных, вентиляционных и электрических сетей здания, перевод ее на электротеплоаккумуляционной обогрев; замена радиаторов отопления, установка приборов учета энергоресурсов и воды, внедрение многотарифного учета электроэнергии; строительство или модернизация котельной в здании; обустройство или ремонт тепловых пунктов; установления стеклопакетов, балконных блоков и входных дверей [9].

Наибольшее распространение в зарубежной практике при организации деятельности по энергосбережению получила технология энергосервиса, для которого контрольный подмеханизм будет иметь следующие содержание и структуру:

Блок 1. «Привлечение энергосервисных компаний». Госэнергоэффективности способствует внедрению технологии энергосервиса в бюджетной сфере, разработав типовую форму для отображения основной информации об энергопотреблении в зданиях бюджетных учреждений. Облгосадминистрации осуществляют ее заполнение и размещение на официальных сайтах для информирования потенциальных исполнителей энергосервиса о наличии возможностей внедрения энергоэффективных мероприятий на объектах бюджетной сферы. По этим данным энергосервисные компании выбирают наиболее привлекательные объекты в бюджетной сфере для применения энергосервиса.

Для осуществления энергосервиса подаются объявления на украинском и английском языках для размещения на сайте Госэнергоэффективности для привлечения энергосервисных компаний к процедуре открытых торгов или переговорной процедуры закупки услуг энергосервиса. В объявлении о закупке энергосервиса по процедуре открытых торгов указывают минимальный шаг повышения показателя эффективности энергосервисного договора в процессе электронного аукциона в процентах и математическую формулу, для учета показателей других критериев оценки, если такие существуют.

Тендерная документация включает: 1) инструкцию по подготовке тендерных предложений; 2) квалификационные критерии к участникам; 3) 
базовый годовой уровень потребления топливно-энергетических ресурсов и жилищно-коммунальных услуг в натуральной и денежной форме по ценам (тарифам), действующими на дату размещения объявления о проведении процедуры закупки. Он утверждается исполнительным органом местного совета или центральным органом исполнительной власти, в управлении которого находится заказчик энергосервиса путем принятия отдельных решений; 4) информацию по объектам энергосервиса и об оборудованию для поставки и потребления топливно-энергетических ресурсов, на основе которой готовятся тендерные предложения [10]; 5) перечень критериев и методика оценки тендерных предложений по учету других критериев, кроме показателя эффективности энергосервисного договора; 6) срок действия тендерных предложений (не менее 90 рабочих дней с даты раскрытия в электронной системе); 7) язык тендерных предложений; 8) предельный срок для подачи тендерных предложений; 9) информация контактного лица заказчика для общения с участниками процедуры закупки; 10) формулу расчета показателя эффективности энергосервисного договора; 11) требования относительно указания срока энергосервисного договора, величины ежегодных платежей исполнителю, годовой объем сокращения расходов заказчика енергсервиса, объем экономии ТЭР в натуральноми и относительном измерении по годам действия договора, фиксированный процент уменьшения расходов заказчика, который будет выплачиваться от экономии исполнителю, цену энергосервисного договора.

Для закупки энергосервиса по процедуре открытых торгов срок подачи тендерных предложений не может быть менее 30 дней с даты опубликования. Тендерная документация проектного предложения размещается на сайте Госэнергоэффективности. По результатам раскрытия тендерных предложений формируется список участников в порядке возрастания предложенной ими цены (приведенной цены). Протокол раскрытия тендерных предложений формируется и публикуется электронной системой закупок автоматически в день раскрытия предложений. Оценка тендерных предложений осуществляется в автоматическом режиме электронной системой закупок по критериям и методике, определенным заказчиком в тендерной документации, и путем применения электронного аукциона [4].

Бесплатно на сайте в течении дня от принятия решения о намерении заключить договор размещается сообщение о намерении заключить договор. Если объекты энергосервиса находятся в управлении различных распорядителей бюджетных средств, то назначается для процедуры закупки уполномоченное лицо. Уполномоченный заказчик и распорядители бюджетных средств отдельно заключают энергосервисные договора с победителем процедуры закупки относительно объектов, которые находятся в их распоряжении.

При условии применения переговорной процедуры тендерные предложения оцениваются по показателям эффективности энергосервисного договора, что является суммой продисконтированных разниц ежегодного со- 
кращения расходов заказчика и ежегодных платежей исполнителю энергосервиса в течении двадцатилетнего периода от объявления о проведении процедуры закупки услуг энергосервиса, и приведенным показателем эффективности энергосервисного договора, который указывают участники в тендерной предложения учитывая значение других критериев оценки по математической формуле, предусмотренной методикой, указанной заказчиком в тендерной документации.

Предложения размещаются по мере снижения показателя эффективности, в течении одного этапа электронного аукциона участник может повысить значение показателя эффективности энергосервисного договора или приведенного показателя эффективности энергосервисного договора один раз в предложении не менее чем на один шаг от предварительно указанного уровня показателя внося изменения в электронную систему закупок, что заключается в сокращении срока энергосервисного договора, уменьшении ежегодных платежей исполнителю энергосервиса. Заказчик и участник-победитель заключают энергосервисный в течение срока действия его предложения, до 60 рабочих дней от принятия решения о намерении заключить договор.

Блок 2. «Государственная регистрация энергосервисных договоров». Госэнергоэффективность осуществляет ведение и обновление списков эско-компаний, которые могут привлекаться к участию в публичных закупках услуг енргосервиса, обобщает информацию о первых заключенных в Украине договорах энергосервиса, обеспечивает ведение и обнародование Перечня предприятий, осуществляющих услуги по энергетическому аудиту, энергосервису, внедряют системы энергоменеджмента, ведет информационную базу потенциальных объектов энергосервиса (сведения вносятся на основании предоставления заполненной формы, разработанной Госэнергоэффективностью).

Блок 3. «Аккредитация исполнителей энергосервиса». Заказчик энергосервиса до десяти дней от принятия решения относительно намерений заключения договора на закупку энергосервиса с участником-победителем представляет на утверждение Госэнергоэффективности или соответствующему местному совету (относительно объектов в его распоряжении) существенные условия энергосервисного договора, которые утверждают или отказывают в утверждении в срок, не превышающий 60 рабочих дней с даты обращения главного заказчика энергосервиса для их утверждения.

Блок 4. «Мониторинг исполнения договоров энергосервиса». Мониторинг предусматривает оценку соблюдения исполнителем существенных условий договора энергосервиса в процессе его реализации, а именно: 1) осуществление в полном объеме мероприятий по перечню в установленные сроки при внедрении энергосервиса; 2) достижение совокупными расходами на оплату услуг энергосервиса цены энергосервисного договора прекращает его действие; 3) достижение планового уровня снижения затрат на оплату или объемов потребления ТЭР в натуральном выражении от осуществления энергосервиса в разрезе лет действия энергосервисного договора; 4) фиксированного процента сокращения расходов на оплату 
стоимости потребляемых топливно-энергетических ресурсов или жилищно-коммунальных услуг, который подлежит выплате исполнителю энергосервиса; 5) срок действия договора энергосервиса; 6) обеспечение соблюдения согласованных сторонами или определенные законодательством режимов и условий использования ТЭР (воздушно-тепловой режим, искусственное освещение, другие характеристики, соответствующие требованиям в области организации труда, содержания зданий, строений, сооружений) и др.

Блок 5. «Контроль исполнения энергосервисного контракта» предусматривает контроль соблюдения порядка оплаты энергосервиса за счет сокращения потребления и расходов на оплату энергоресурсов или услуг ЖКХ относительно уровня потребления без применения энергосервиса; условий и порядка расторжения энергосервисного договора, своевременности и полноты возмещения убытков, компенсаций или иных платежей за энергосервисным договором; порядка предоставления заказчику имущества, имущественных прав и ценностей, созданных за энергосервисным договором; порядка корректировки расчета результатов осуществления энергосервиса при изменениях в процессе реализации климатических условий, температуры наружного воздуха, назначения объекта энергосервиса, в конструкции или площади, порядка или режима работы объекта энергосервиса и тому подобное; порядка и методов измерения (расчета) и проверки фактического уровня сокращения потребления или расходов заказчика на оплату топливно-энергетических ресурсов и жилищно-коммунальных услуг в результате осуществления энергосервиса по сравнению с потреблением и затратами, которые были бы осуществлены при отсутствии энергосервиса. Важную роль играет контроль выполнения обязательств по энергосервисныму договору сторонами.

Фиксированный процент, по которому определяют сумму платы исполнителю энергосервиса, не может быть ниже 80 процентов суммы сокращения расходов заказчика энергосервиса на оплату соответствующих энергетических ресурсов или жилищно-коммунальных услуг. При условии частичного финансирования мероприятий по энергосбережению на объекте за бюджетные средства, заказчику разрешается определять максимальный размер фиксированного процента меньше 80\%. Срок действия энергосервисного договора должен быть не более 15 лет.

При недостижении планового уровня экономии потребления ТЭР или расходов на оплату жилищно-коммунальных услуг из-за неэффективности энергосервиса, при нарушении условий энергосервисного договора исполнителем энергосервиса, последний должен ликвидировать нарушения, в том числе путем применения дополнительных мер энергосервиса или оплатить заказчику сумму разницы между фактическим уровнем сокращения стоимости потребления ТЭР или расходов на оплату жилищно-коммунальных услуг и уровнем сокращения, вычисленным по условиям энергосервисного контракта.

Выводы и направления дальнейших исследований. Предложено рассматривать контрольный подмеханизм как совокупность функций контроля и 
мониторинга деятельности субъектов управления энергосбережением разных уровней, который реализуется через формирование информационной базы данных об эффективности действия МУЕСВУЗ и реализацию политики энергосбережения.

Согласно результатам исследования контрольного подмеханизма МУЕСВУЗ, который реализуется Госэнергоэффективностью, выделены пять блоков: 1) привлечение к деятельности по энергосбережению; 2) государственная регистрация; 3) аккредитация и реализация деятельности по энергосбережению; 4) мониторинг в сфере энергосбережения; 5) контроль в сфере энергосбережения - в разрезе которых распределены задачи и функции энергосбережения.

Анализ реализации концепции перфоманс-контрактинг в украинских реалиях позволил определить особенности организации контроля при использовании энергосервисных договоров, что разрешило выделить пять основных блоков. Изучение взаимодействия субъектов и объектов энергосбережения в пределах энергосервиса проявило роль отдельных субъектов энергосбережения, особенности принятия, согласования, регламентирования и реализации управленческих решений. Выделение блоков контрольного подмеханизма в реализации технологии энергосервиса подтвердило соответствие проведенной структуризации контрольному подмеханизму, который реализуется Госэнергоэффективностью в процессе выполнения основных задач и функций, что делает возможным совершенствование и систематизацию законодательно-нормативного обеспечения энергосбережения.

Указанный подход следует распространить на все технологии и инструменты функционального подмеханизма МУЕСВУЗ.

References:

[1] 0 внутреннем и внешнем положении Украины в 2015 году: Аналитический доклад к Ежегодного Послания Президента Украины в Верховную Раду Украины [Текст]. - М .: НИСИ, 2015 - 684 с.

[2] О Национальной комиссии, осуществляющей государственное регулирование в сфере энергетики и коммунальных услуг: Закон Украины // Ведомости Верховной Рады (ВВР). - 2016. - №51. - 83 с. - Режим доступа: http://zakon5.rada.gov.ua/laws/show/1540-19.

[3] Задачи и функции [Электронный ресурс] / Госэнергонадзор. - Режим доступа: https://den.energy.gov.ua/home/zavdannya-ta-funktsiji.

[4] О публичных закупках: Закон от 25.12.2015 № 922-VIII [Электронный ресурс] // Ведомости Верховной Рады (ВВР). - 2016. - № 9. - 3 с. - Режим доступа: http://zakon3.rada.gov.ua/laws/show/922-19.

[5] Положение о Государственном агентстве по энергоэффективности и энергосбережению Украины [Электронный ресурс]: Утверждено постановлением Кабинета Министров Украины от 26 ноября 2014 № 676. - Режим доступа: http://saee.gov.ua/uk/about/polozhennya- derzhenerhoefektyvnosti-ukrainy.

[6] 0 программах повышения энергоэффективности и уменьшения потребления энергоресурсов: Распоряжение Кабинета Министров Украины от 17 декабря 
2008 № 1567-p. [Электронный ресурс] / КМУ. - М. - Режим доступа: http://zakon2.rada.gov.ua/laws/show/1567-2008-\%D1\%80.

[7] Об энергосбережении: Закон Украины от 1 июля 1994 № 74/94-ВР (с изм. И доп.) [Электронный ресурс] // Ведомости Верховной Рады Украины (ВВР). - 1994. - № 30. - 102 с. - Режим доступа: URL: http://zakon4.rada.gov.ua/laws/show/74/94\%D0\%B2\%D1\%80.

[8] О комбинированном производстве тепловой и электрической энергии (когенерации) и использовании сбросного энергопотенциала: Закон Украины от 5 апреля 2005 г. № 2509-IV [Электронный ресурс] // Ведомости Верховной Рады Украины (ВВР). - 2005. - № 20. - Режим доступа: http://saee.gov.ua/documents/laws/Zakon-4.doc.

[9] 0 продлении срока выполнения Государственной целевой экономической программы энергоэффективности и развития сферы производства энергоносителей из возобновляемых источников энергии и альтернативных видов топлива на 2010-2015 годы: Постановление Кабинета Министров Украины от 11.11.2015 № 929 [Электронный ресурс] / Кабинет министров Украины. - М., 2015, ноябрь. - 3 c. - Режим доступа: http://saee.gov.ua/sites/default/files/KMU_929.zip.

[10]0 введении новых инвестиционных возможностей, обеспечение прав и законных интересов субъектов предпринимательской деятельности для проведения масштабной энергомодернизации: Закон Украины от 9 апреля 2015 № 327-VIII [Электронный ресурс] // Ведомости Верховной Рады (ВВР). - 2015. - № 26. - Режим доступа: http://zakon3.rada.gov.ua/laws/show/327-19. 